\title{
5 DAÑOS Y PERJUICIOS \\ EN LA RESOLUCIÓN \\ Rodrigo Martín Pellejero CONTRACTUAL POR INCUMPLIMIENTO. \\ REVISITANDO EL PLENARIO "CIVIT", MÁS DE VEINTE AÑOS DESPUÉS, A LA LUZ DEL NUEVO CÓDIGO CIVIL Y COMERCIAL
}

RESUMEN

El problema de las consecuencias de la extinción de un contrato por resolución por vía de pacto o facultad comisoria ha quedado notoriamente influido por la doctrina del plenario "Civit", que limitó la posibilidad de reclamar indemnizaciones. La reforma del Código Civil y Comercial permite evolucionar hacia una flexibilidad mayor y una nueva mirada.

PALABRAS CLAVE Resolución contractual · pacto comisorio - facultad comisoria · extinción · indemnización de daños y perjuicios · restitución

\section{ABSTRACT}

The matter about the consequences of the termination of a contract for breach has been widely influenced by the rule of the "Civit" precedent, which limited the damages awarded to the non breach party. The reform of the Civil and Commercial Code allows an evolution towards to a greater flexibility and a new look into the matter.

\section{KEY WORDS}

Termination for breach of contract

- termination clauses - cancelation

- damages for breach - restituion 


\section{Introducción}

Los temas relacionados con las consecuencias del incumplimiento y la responsabilidad contractual son importantes tanto desde el punto de vista teórico como práctico. Desde el primero de estos puntos de vista, la importancia radica en que las consecuencias del incumplimiento contractual ponen en crisis la idea misma del contrato y sus efectos obligatorios $^{1}$. Desde el punto de vista práctico, los "casos" contractuales, es decir los casos conflictivos o litigiosos, giran generalmente en torno a la problemática del incumplimiento y sus consecuencias.

Cuando como consecuencia del incumplimiento de una de las partes la otra parte del contrato opta por la resolución contractual, sea por vía de la existencia de un pacto comisorio o por vía de la facultad comisoria con base en el art. 1204 del Código Civil o del art. 216 del Código de Comercio, se produce la extinción del contrato con efectos retroactivos. Frente a este supuesto se plantea la duda respecto de los efectos de la resolución contractual, tanto en cuanto al régimen de la restitución como a la posibilidad de reclamar la indemnización de daños y perjuicios. Es precisamente, respecto de este último punto que existe una controversia con opiniones disímiles que van desde quienes piensan que en estos casos la parte "in bonis" no tiene derecho a reclamar daños y perjuicios, pasando por quienes sostienen que puede reclamarlos pero dentro de ciertos límites estrechos, hasta quienes consideran que no existen limitaciones especiales en este caso que acoten el derecho a la indemnización.

En el subtítulo de este trabajo hago referencia al pleno "Civit" que ha abordado puntualmente la cuestión, siendo un fallo insoslayable en la cuestión, aunque ha sido objeto de interpretaciones disímiles.

\section{La opinión de Llambías y el fallo "Firpo c. Hahn"}

Jorge J. Llambías de manera muy sucinta se refiere al tema de este artículo en su obra sobre Obligaciones ${ }^{2}$, para sostener que en el caso puede

1 Desde el Derecho y Economía, POSNER, Richard A. Economic Análisis of Law. $5^{\circ}$ ed. Nueva Cork. Ed. Aspen Law. 1998. p. 101, explica que la función del derecho contractual es, precisamente, asegurar remedios eficientes para evitar que el comportamiento oportunista de alguna de las partes haga que pierda sentido confiar en los co-contratantes.

2 LLAMBÍAS, Jorge J. Tratado de Derecho Civil Obligaciones, T I. $5^{\circ}$ ed. Buenos Aires. Ed. Perrot. p. 296. 
reclamarse la indemnización del "daño al interés negativo". Como fundamento de esta conclusión remite al fallo que dictara como integrante de la Sala A de la Cámara Nacional Civil ${ }^{3}$.

El fallo en cuestión es relativo a una disputa originada en el incumplimiento de las obligaciones derivadas de un boleto de compraventa. El vendedor entendió que el comprador estaba en mora en su obligación de escriturar y le notificó la resolución del contrato, a lo que el comprador se opuso. Posteriormente el comprador notificó la designación de un escribano para el otorgamiento de la escritura y lo citó al vendedor para otorgarla. Este último se negó. Finalmente, el comprador inicia juicio de escrituración, introduciendo de manera subsidiaria la pretensión de que, para el caso que la escrituración fuera imposible, se rescindiera el contrato con más todos los daños y perjuicios acarreados por la pérdida del inmueble. Estos son los hechos relatados en el fallo.

En su voto ${ }^{4}$ Llambías entendió que la pretensión del actor era contradictoria, porque

...si se reclamaba la extinción del contrato por la vía de su rescisión, o mejor dicho su resolución, no podía aspirarse a obtener el resarcimiento patrimonial tendiente a cubrir el incremento que el cumplimiento del contrato le habría reportado al actor. La indemnización de daños y perjuicios es viable en uno u otro supuesto, pero su cuantía será diferente según que se trate de la resolución, o rescisión del contrato, o que se trate del cumplimiento del mismo por la vía sustitutiva de la condigna reparación de los perjuicios causados. En el primero de los casos se tratará de restituir a las partes a la situación anterior a la celebración del contrato, de manera que una de ellas no sufra menoscabo por la celebración de ese contrato que ha resultado disuelto por culpa de la otra. En el segundo de los casos se tratará de colocar a las partes en la situación en que habrían quedado si se hubiese cumplido realmente el contrato. En el primer caso se reintegrará a la parte inocente de la rescisión, los gastos que ella ha efectuado con motivo y en vista de un contrato que ha resultado desvanecido, es decir, el "interés negativo" de que hablaba Ihering (Ouvres Choisies, Paris, 1893, T. II, pp. 1 sgtes.). En tanto que en el segundo caso, sin atender a las erogaciones efectuadas por la parte

3 CNCiv. Sala A, agosto, 7, 1958, Firpo c/ Hahn, La Ley 93, p. 685

4 Aun a riesgo de ser tedioso, me pareció oportuno transcribir literalmente una parte importante de ese voto, porque allí está la explicación teórica de la posición, que no se encuentra en la obra doctrinaria del autor. 
inculpable del incumplimiento del contrato, se resarcirá a ella en forma tal que su situación patrimonial quede como si el contrato se hubiere realizado.

Es notable que el fallo, pese a tan clara toma de posición, finalmente decide en contra de dicha postura teórica. En efecto, la solución concreta del caso es que se reconoce al actor, frente a la extinción del contrato, el derecho de ser indemnizado de la diferencia del mayor valor que el inmueble adquirió entre la fecha de compra y el momento de la sentencia (este último valor surgía en el caso del hecho que el inmueble había sido vendido a un tercero por un valor superior al del contrato originario). Y esto lo justifica explicando que la acción resarcitoria “...se refería, no a la rescisión impropiamente mentada, sino al intencionado incumplimiento del contrato...". Pareciera que en concreto el fallo pasa a indemnizar este supuesto claro de extinción del contrato de manera idéntica a como indemnizaría en un caso de incumplimiento de un contrato no resuelto, en el que se condena a pagar la indemnización sustitutiva de la prestación. Para esto invoca el art. 889 del Código Civil, que no es otra cosa que un caso de indemnización del daño al "interés positivo" o de cumplimiento. Advertimos, en suma, que este precedente en el que se sienta una idea restrictiva respecto de la indemnización de los daños y perjuicios en caso de resolución contractual, a los fines prácticos se aparta de ese criterio teórico para conceder una indemnización de lucro cesante del interés positivo o de cumplimiento.

\section{Civit c. Progress y sus circunstancias}

El pleno de la Cámara Nacional de Apelaciones en lo Civil del 22/2/1990, dictado en la causa "Civit, Juan c/ Progress S.A. y Ot."5 resulta un hito insoslayable en esta temática.

Ese plenario sentó como doctrina legal aplicable la siguiente: "Al declararse la resolución del contrato por el ejercicio del pacto comisorio, es viable el resarcimiento del lucro cesante por los daños y perjuicios ocasionados durante el tiempo en que perduró la mora del contratante incumplidor"

Vázquez Ferreyra ${ }^{6}$, confirmando la trascendencia del pleno, nos advierte que este es un fallo que no puede ser pasado por alto por el estudioso o el práctico del derecho de daños.

5 La Ley 1990-D, 474

6 VÁZQUEZ FERREYRA, Roberto. “Incumplimiento Contractual y Responsabilidad por Daños” en La Ley Litoral. 1997. p.185. 
El fallo viene a superar algunas estrecheces en la interpretación del derecho en cuanto a la indemnización de las consecuencias del incumplimiento. Este fallo, sin embargo, muchas veces ha sido entendido como ratificando el criterio de que en estos supuestos el acreedor que resuelve el contrato sólo tiene derecho a la indemnización del daño al interés negativo, tal como en teoría lo sostenía Llambías. Precisamente, el primer apartado de los fundamentos de la mayoría hace expresa referencia a la opinión doctrinaria del mencionado autor y al fallo que hemos visto, para sostener que esa postura “...no se ajusta a los términos de la ley civil". Entonces, claramente, "Civit c. Progress" es una superación del criterio antes expuesto.

\section{La mayoría de manera impersonal y los fundamentos de Bueres}

Mosset Iturraspe ${ }^{7}$ critica la oscuridad de los diversos fundamentos expuestos por los camaristas, tanto a favor como en contra de la solución mayoritaria y destaca la claridad con que se expresa la mayoría en forma impersonal. Esta mayoría descarta claramente que en el caso de resolución contractual la indemnización deba limitarse al daño emergente o al interés negativo y admite que debe indemnizarse el lucro cesante.

El principal argumento normativo para sostener esta interpretación se basa en que el art. 1204 del Código Civil, prevé que el acreedor puede reclamar al incumplidor el cumplimiento del contrato o la resolución y, en ambos casos, con "...el derecho a reclamar el resarcimiento de los daños y perjuicios". Por otro lado entienden que la solución que proponen es la que mejor se concilia con el principio de la reparación integral de los perjuicios y en la idea de que no debe dar lo mismo que el deudor cumpla o que no lo haga.

Alberto Bueres formó parte de esa mayoría, pero consideró necesario explicar sus propios fundamentos. A diferencia de la mayoría impersonal, Bueres rescata el distingo entre el "daño al interés positivo" y el "daño al interés negativo", para sostener que cuando el acreedor pide la ejecución directa de la obligación o su sustituto indemnizatorio (art. 505 inc. 3, C. Civil) su reclamación se ubica dentro de la categoría del "daño al interés positivo". "Muy distinto -sostiene- es el panorama que se presenta cuando se produce la resolución del contrato, pues en estos casos el reclamo resar-

7 MOSSET ITURRASPE, Jorge. "Incumplimiento, resolución y lucro cesante" en La Ley 1990-D, 1064. 
citorio ha de encasillarse en el "interés negativo o interés de confianza"”. Pero a renglón seguido explica que este último concepto no debe limitarse al daño emergente (gastos) sino también al lucro cesante que explica como el caso en que el acreedor "...tiene en vista la realización de un negocio concreto (lucro cesante) y espera que el co-contratante-incumplidor-cumpla, o cuando ese acreedor posee la "chance" de obtener una ganancia..."

El concepto de daño al interés negativo que maneja Bueres es amplio, no está basado en la mirada hacia atrás o hacia el futuro, no se limita a lo que sea anterior o posterior a la celebración del contrato, sino que se extiende "...a todos los daños sufridos por el acreedor a causa de haber confiado en la vigencia de un contrato que no se concretó o que se extinguió" Es decir, que la opinión de Bueres, a los fines prácticos, coincide con la de la mayoría en el sentido que si bien entiende que en casos de resolución del contrato el acreedor tiene una pretensión indemnizatoria limitada por el "interés negativo", este es suficientemente amplio como para abarcar tanto el daño emergente como el lucro cesante. Y este último rubro del daño no lo entiende Bueres limitado a la mera pérdida de chance, sino también a la concretar pérdida de ganancias esperadas.

Con lo que venimos diciendo se ve la solución propuesta por Bueres en realidad no dista mucho de la solución concreta propuesta por Llambías en el fallo antes recordado.

\section{La tesis restrictiva}

Hay una tesis restrictiva, que también podríamos llamar "negatoria" que llanamente niega que el acreedor que opta por la resolución tenga derecho a ser indemnizado. Esta ha sido la posición del voto en disidencia de los doctores Sansó, de Mundo, Lozano y Gárgano, en el recordado plenario "Civit". Parecieran basar su postura en el hecho de que el contratante no tendría asegurado un resultado positivo derivado de la contratación, por lo que si decide dejar si efecto esta (resolviéndola) no tiene derecho a indemnización de eventuales daños y perjuicios.

En el derecho comparado, los parágrafos 325 y 326 originales del BGB alemán sostenían escuetamente esta tesis, aunque puesta en duda por sus intérpretes. ${ }^{8}$ Como veremos luego, la reforma del derecho de obligaciones de ese país del año 2001 modificó drásticamente esta solución.

8 PANTALEÓN, Fernando. "Resolución por Incumplimiento e Indemnización" en Anuario de Derecho Civil 1989. IV. p. 1150 


\section{La tesis del daño al interés negativo}

Esta tesis tiene en la recordada opinión de Llambías a su gran defensor. En el plenario "Civit" el voto del Dr. Greco magistralmente defiende esta tesis. La misma tiene gran cantidad de prestigiosos adherentes en la doctrina autoral nacional9.

Esta tesis ve una contradicción entre la extinción del contrato con efecto retroactivo y la posibilidad de reclamar la indemnización de daños y perjuicios contractuales en base a dicho contrato extinguido. Greco entiende que de este modo se evita que el contrato para uno “...queda resuelto; para el otro queda vigente. O sea que se resarce dos veces”. El núcleo de este razonamiento pareciera radicar en el efecto retroactivo que se atribuye a la resolución contractual. Si el contrato se extingue con efectos hacia el pasado, de manera de colocar a las partes en la misma situación en que estaban al momento inmediatamente anterior a contratar: ¿cómo puede explicarse que el acreedor tenga derecho al resarcimiento de lucro que hubiera obtenido del contrato extinguido?.

Jordano Fraga ${ }^{10}$ expone esta idea con gran precisión

Para mí resulta claro que aquello que se indemniza es el interés contractual negativo, los daños causados por la resolución, por la celebración del contrato inválido. Si hablando de otras causas de ineficacia (nulidad, anulabilidad) se afirma la responsabilidad por el interés contractual negativo (...), podemos aplicar esos mismos principios a la particular causa de ineficacia del contrato constituida por la resolución.

La lógica de esta posición descansa en el énfasis en el efecto extintivo retroactivo propio de la resolución: si la resolución borra con efecto retroactivo el contrato como si éste no hubiera existido, parece incoherente que

9 TRIGO REPRESAS, Félix A. y LÓPEZ MESA, Marcelo J. Tratado de la Responsabilidad Civil. T. II. Ed. La Ley. p. 154

...frente al incumplimiento de obligaciones nacidas de un contrato, el acreedor tiene en algunos supuestos la posibilidad de resolver el negocio -doctrina de los arts. 1204 del Cód. Civil y 206 del de Comercio y concordantes-, quedando entonces enmarcada su pretensión resarcitoria dentro del daño al interés negativo" En el mismo sentido, Nicolau, Noemí, Fundamentos de Derecho Contractual, T. I, ed. La Ley, 2009, p. 357: “La parte no incumplidora puede reclamar daños y perjuicios, pero como el contrato se resuelve y los efectos son retroactivos no se puede exigir el daño al interés positivo, que es el de cumplimiento, sólo se reclama el daño al interés negativo.

10 Citado por PANTALEÓN. Op. cit. p. 1166. FRAGA, Jordano. Cuadernos Civitas de Jurisprudencia Civil. 15. 1987. p. 5194. 
una de las partes tenga derecho a la indemnización del lucro (frutos, aumentos de valor, etc.) que hubiera obtenido como consecuencia del contrato.

Manuel Cornet, en una obra específica sobre el tema ${ }^{11}$, adhiere puntualmente a la tesis que limita el resarcimiento al "daño al interés negativo". Lo hace con estas elocuentes palabras

No es posible que el acreedor resuelva el contrato y obtenga lo que esperaba si el contrato se cumplía; le estaríamos restituyendo lo que entregó y además le daríamos la prestación de la otra parte, con lo cual se estaría enriqueciendo sin justa causa a costa del culpable. ... Si se resuelve, se está descartando el exigir el cumplimiento, de allí que se trate de una opción y es el contratante inocente quien estimará lo que le conviene...

En definitiva esta tesis entiende que el acreedor, si pudiera reclamar el interés positivo o de cumplimiento en caso de resolución, estaría acumulando lo recibido por restitución con la prestación a cargo de la contraparte y, al mismo tiempo, liberándose de la obligación.

\section{La tesis del daño al interés positivo}

Entiendo que "Civit" debe interpretarse como la consagración de la tesis de la resarcibilidad del lucro cesante, como parte del interés positivo. Como hemos visto supra, esa es la posición que define la mayoría de manera impersonal.

En la doctrina nacional esta posición cuenta con el importante apoyo de Atilio Alterini ${ }^{12}$.

Entendemos que los autores como Bueres o Cornet $^{13}$ que sostienen la posición de la limitación de la indemnización al daño al interés negativo pero, que al mismo tiempo, admiten sin limitaciones la indemnización del lucro cesante sufrido por el contratante cumplidor, no están en los hechos

11 CORNET, Manuel. Efectos de la Resolución de los Contratos por Incumplimiento. Ed. Marcos Lerner. p. 203.

12 ALTERINI, Atilio A. Contratos. Abeledo Perrot. p. 512: "La parte no incumplidora tiene derecho a ser indemnizada por la parte incumplidora, tanto en el caso de cumplimiento tardío (art. 1204, 3er. párr., Cód. Civil, daño moratorio) como en el caso de resolución del contrato (art. art. 1204, 2 do. párr., Cód. Civ., daño compensatorio). El daño compensatorio comprende todos los rubros del la reparación plena...

13 CORNET, Manuel. Op. cit. p. 206: donde asume que si se admite en el interés negativo la procedencia del "lucro cesante", “...la diferencia entre una y otra postura se achica”. 
demasiado lejos de las posturas que admiten la resarcibilidad del daño al interés positivo.

Ahora bien como enseña Brebbia ${ }^{14}$, la misma noción de daño al interés negativo introducida por Ihering, es interpretada por muchos autores como comprensiva del daño emergente y también del lucro cesante, aunque también otros interpretan que debe limitarse solo a los gastos (daño emergente). El citado autor, sin embargo, explicita la idea de que el lucro cesante puede comprender tanto los casos de interés negativo como los de interés positivo, aunque en el primer caso está limitado por aquello que “... el acreedor hubiera tenido si no hubiese confiado en los tratos preliminares frustrados..." ${ }^{15}$.

Esta tesis, para evitar caer en situaciones en las que el acreedor se enriquezca con la indemnización, tiene que admitir que frente a la resolución del contrato el acreedor puede reclamar el daño al interés positivo, pero obviamente no la prestación específica ni tampoco el equivalente dinerario de ésta. Esto es así porque en todos estos casos nos encontramos frente a contratos bilaterales, o con prestaciones recíprocas, en los que la prestación a que se obliga una parte tiene su correlato en la del otro, con lo que ese equilibrio se rompería injustamente si una parte pudiera liberarse de su obligación (u obtener la restitución de lo dado) y, al mismo tiempo, obtener de la otra la prestación específica o su equivalente en dinero. Lo que el acreedor puede reclamar como indemnización es la ganancia que esperaba obtener del contrato (intereses moratorios, mayor valor de reventa de la cosa, utilidad que hubiera obtenido de la misma, etc.), siempre que no reclame la prestación en sí o su equivalente. Esto indica, como intentaré explicar más abajo, que existe una clara correlación entre el efecto restitutorio (y la consiguiente liberación de obligaciones pendientes) y la posibilidad de reclamar daños y perjuicios ${ }^{16}$.

Los Principios de Derecho Europeo de los Contratos (PECL, por sus siglas en inglés) expresamente establecen (art. 9:305, efectos de la extinción en general) como consecuencia de la resolución del contrato por

14 BREBBIA, Roberto. Responsabilidad Precontractual. Ed. La Rocca. 1987. p. 49.

15 BREBBIA. Op. cit. p. 221.

16 GÓMEZ POMAR, Fernando. "El incumplimiento contractual en Derecho Español" en Revista para el Análisis del Derecho. Barcelona, Julio de 2007, p. 30: “El contratante insatisfecho que resuelve el contrato podrá igualmente obtener la indemnización de aquellos perjuicios que la restitución de prestaciones que, normalmente, acompañará a la resolución, no esté en condiciones de eliminar para colocar al contratante en la situación de utilidad que tras la plena realización del contrato hubiera podido aprovechar." 
incumplimiento la liberación de las obligaciones pendientes de ambas partes, pero dejando a salvo el derecho de exigir las indemnizaciones que se hubieran originado hasta el tiempo de la extinción. En todo caso, estas normas no dejan lugar a dudas de la posibilidad para el acreedor de obtener el resarcimiento de la ganancia que hubiera obtenido ya sea de un negocio concreto o por diferencia con el valor de mercado (market rule) ${ }^{17}$, lo que incuestionablemente excede el estrecho marco del daño al interés negativo.

\section{Conclusión sobre la indemnización de daños ante la resolución}

Habiendo pasado revista a las distintas posiciones sobre el punto, es hora de intentar sacar algunas conclusiones.

La tesis negatoria, que encontró su criticado antecedente más lejano en el BGB, pareciera no tener andamiaje frente a los claros textos de los arts. 1204 del C. Civil y 216 del C. de Comercio que expresamente refieren a la posibilidad de que el acreedor reclame la indemnización. Por lo demás, no existe norma alguna que expresamente lleve a la conclusión de que el cumplidor que opta por la resolución no pueda exigir la indemnización de los daños sufridos.

La tesis de la limitación de la indemnización al "daño al interés negativo" parece criticable, por cuanto traslada al momento del cumplimiento (o incumplimiento) de un contrato ya perfeccionado, conceptos que fueron pensados para la etapa previa a la celebración del contrato. Es que, precisamente, la propia idea de Ihering del "daño al interés negativo" diferenciado del "daño al interés positivo" se basa en poder distinguir la responsabilidad precontractual, que por definición refiere a un contrato aún no celebrado o celebrado inválidamente, de la responsabilidad contractual, que toma como punto de partida un contrato celebrado y válido. Entonces el concepto de "daño al interés negativo" (aún abarcando el lucro cesante) aparece como demasiado estrecho para el caso que nos ocupa, como para dar una respuesta satisfactoria. Entiendo que la posición que critico hace una equiparación entre los contratos no celebrados o celebrados inválidamente, con los contratos ineficaces por ineficacia sobrevenida (resolución), en los que la extinción se produce de manera retroactiva. Se trata

17 SOLER PRESAS, Ana. "La indemnización por resolución del contrato en los PECL/DCFR" en Revista para el Análisis del Derecho. Barcelona, mayo de 2009. 
de la idea de que la resolución extinguiría el contrato "como si este nunca hubiera existido", lo cual no es del todo cierto por cuanto: a) las prestaciones divisibles y equivalentes que se hubieran cumplido quedan firmes y no son alcanzadas por el efecto restitutorio (arg. art. 1204 C. Civil); b) si algún tercero hubiera adquirido un derecho en relación con el contrato, éste derecho no caerá automáticamente; c) si en el contrato hubieran existido previsiones como el mismo pacto comisorio o sobre conflictos como cláusulas penales, prórrogas de competencia, etc., las mismas seguirán operando aún con el contrato extinguido por resolución. Es decir, que la continuación de algunos efectos del contrato extinguido por resolución demuestra que es una exageración sostener que debe considerarse que el contrato se extingue como si no hubiera existido y que resultaría contradictorio admitir el derecho a reclamar indemnizaciones en base al contrato.

Por lo dicho, la propuesta de este trabajo, a manera de conclusión, es abandonar los conceptos "interés positivo" o "interés negativo" para analizar al problemática aquí planteada, ya que dicho conceptos -que resultan útiles y adecuados para distinguir la responsabilidad precontractual de la contractual- crean confusión en este tema y además ocasionan artificiosas limitaciones a la hora de resarcir los daños sufridos por la parte cumplidora.

Creo que lo más adecuado será volver a los conceptos de daño emergente y lucro cesante, para aplicarlos a los casos de pretensiones de indemnización derivadas de un contrato resuelto por incumplimiento. Ahora bien, coincido con los autores que mayoritariamente se enrolan en la tesis del "daño al interés negativo" en que no es lo mismo desde el punto de vista de la indemnización que el contratante cumplidor exija el cumplimiento específico del contrato con más daños y perjuicios moratorios (o el cumplimiento por equivalente cuando el específico no puede obtenerse o ha perdido utilidad o interés para el acreedor), que opte por la extinción del contrato por la vía de la facultad comisoria o el pacto comisorio. Pero en este último caso, la diferencia con los anteriores no radicará tanto en considerar que "el contrato nunca hubiera existido", como en los límites que impone de hecho el efecto restitutorio.

Por lo demás, no debemos olvidar que nos encontramos frente al caso de un contrato que se ha extinguido por un incumplimiento que es reprochable al deudor (sea a título de culpa o de algún factor objetivo de atribución), por lo que ese reproche trae como consecuencia que deba indemnizar las consecuencias negativas que el acreedor ha experimentado, 
derivadas como consecuencia de ese incumplimiento. No puede dar lo mismo que el contrato esté o no celebrado (por más que se extinga retroactivamente) o que el mismo se cumpla o se incumpla.

\section{Los límites que impone el efecto restitutorio}

Se ha sostenido la independencia entre los efectos restitutorios propios de la resolución y los efectos indemnizatorios ${ }^{18}$. Esto es así, en el sentido de que no es válido "retener" bienes o dinero que deberían ser restituidos, a cuenta de daños y perjuicios que no estén debidamente reconocidos. Sin embargo, la relación entre los efectos restitutorios e indemnizatorios es íntima, como hemos dicho antes, por cuanto quien recupera todo o parte de la prestación entregada, reduce los daños a reclamar en la medida del valor actual de esos bienes.

La extinción del contrato por resolución por incumplimiento produce: a) la liberación de las partes de las obligaciones aún no cumplidas; b) la obligación de restituirse mutuamente lo que hasta ese momento se hubiera entregado en virtud de las obligaciones contractuales; y c) la obligación para el culpable de indemnizar los daños y perjuicios causados.

El primero de estos efectos, pone un límite al efecto indemnizatorio, ya que al producir la "liberación" de los contratantes, les permite disponer de los bienes por otros títulos ${ }^{19}$, produciendo una mitigación de los daños. El culpable responderá de los daños en la medida en que los mismos se encuentren en relación adecuada de causalidad, lo que necesariamente implica que se encuentre dentro de los límites de la previsibilidad ${ }^{20}$ Este criterio de la previsibilidad impide que el contratante que puede disponer libremente de los bienes que deberían haber estado comprometidos en el contrato frustrado, reclame una indemnización sustitutiva de su valor total si puede colocarlos en el mercado. Esta regla de mercado o "market rule" ${ }^{21}$ permite, entonces, al contratante perjudicado reclamar la indemnización al culpable, deduciendo el valor de la colocación de esos

18 MÉNDEZ SIERRA, Eduardo Carlos. “La Resolución por Incumplimiento y su Efecto Restitutorio” en La Ley.

19 MÉNDEZ SIERRA. Op. Cit.

20 ACUÑA ANZORENA, Arturo. "La Previsibilidad como Límite de la Obligación de Resarcimiento en la Responsabilidad Extracontractual” en Estudios sobre la Responsabilidad Civil. Ed. Platense. 1963. p. 41 y MÉNDEZ SIERRA, Eduardo Carlos. "El Daños Contractual Resarcible "Hadley v. Baxendale" y nuestro art. 520 del Cód. Civil” en El Derecho. T. 200. p. 38

21 SOLER PRESAS. Op. Cit. p. 5 
bienes en el mercado (allí entrará a jugar la cuestión del mayor o menor valor de esos bienes de acuerdo a las oscilaciones de mercado). Así, la liberación de la obligación pendiente de entrega de la totalidad o parte de las cosas vendidas, frente a un contrato resuelto por incumplimiento del comprador, le permitirá al vendedor volver a disponer de estas cosas por otro contrato, lo que implicará una mitigación de sus daños, reduciendo éstos sólo a la diferencia con ese valor de mercado o colocación.

Algo similar ocurrirá con el efecto restitutorio de los bienes entregados antes de la resolución. Es que al obtener la restitución de los bienes entregados, el valor de éstos (sea por la propia utilidad que representan o por su valor de mercado) operará como un límite a la hora de pretender la indemnización de daños y perjuicios, la que quedará reducida a su menor valor actual o al resarcimiento de la pérdida del uso hasta la restitución, etc. Recuérdese que aún Llambías en el recordado caso "Firpo c. Hahn" en definitiva, más allá de los rótulos teóricos, llega a esta solución indemnizatoria.

\section{La reforma del BGB}

"En un contrato bilateral, el derecho de exigir la reparación de daños, no quedará excluida en caso de resolución" ${ }^{22}$. Este es el actual texto del parágrafo 325 del BGB alemán, desde que su reforma entrara en vigor el 1 de enero de 2002.

Con la reforma de esta norma desaparece el texto normativo fundamental que en el derecho comparado daba pábulo a la tesis negatoria ${ }^{23}$, como hemos visto más arriba.

Ya antes de esta reforma la doctrina alemana ${ }^{24}$ relativizaba la limitación impuesta por su Código Civil, excluyendo de su aplicación los casos en que el contrato se extinguía sin cumplimiento de las prestaciones y admitiendo la indemnización por culpa in contrahendo.

La mencionada reforma ha alterado el panorama de modo tal que no quedan duda que una vez extinguido el contrato y concurriendo los requisitos que hacen posible la reparación de daños y perjuicios, estos son

Agradezco a Lissi Geiger, paciente y esforzada Profesora de Alemán, haber colaborado en la traducción del texto y haber esclarecido otras nociones en ese idioma.

23 LAMARCA Y MARQUÉS, Albert. "Entra en vigor la ley de modernización del derecho alemán de obligaciones" en Revista para el Análisis del Derecho, 10/1/2002. Puede verse en www.indret.com/es/ PANTALEÓN, Fernando. Op. Cit. p. 1150. 
admitidos sin siquiera la limitación al daño al interés negativo. ${ }^{25}$ De este modo el derecho alemán parece haber superado definitivamente la dicotomía entre la resolución del contrato por incumplimiento y la posibilidad de reclamar la indemnización de los daños y perjuicios sufridos. La creatividad de la doctrina y jurisprudencia de ese país había superado estas deficiencias en la práctica mediante la creación de la "Differenztheorie" ${ }^{26}$. Sin embargo, la reforma reconcilia el texto legal con el pensamiento científico y la práctica de los tribunales.

\section{El common law}

Las soluciones que sobre el punto brinda este sistema son algo difíciles de comparar con las de la familia del derecho romano continental, en la medida en que el common law frente al incumplimiento contractual posee un planteo totalmente diferente. Este planteo se centra en los "remedies", es decir, en las herramientas que el derecho brinda el acreedor frente al incumplimiento de su co-contratante. Entre esas herramientas, el cumplimiento específico ("specific performance") es solo una de las soluciones posibles y ciertamente, la última de ellas, prevista para casos especiales. Por ello, la cuestión que origina este trabajo no se plantea puntualmente en este derecho. Frente al incumplimiento el acreedor en primer término tiene derecho a la indemnización de daños y perjuicios. Esto se da así tanto frente a un incumplimiento total como parcial ${ }^{27}$.

Calamari y Perillo ${ }^{28}$ enseñan que frente al incumplimiento del demandado los derechos contractuales primarios del actor son desechados y en sustitución la ley concede derechos secundarios. Estos son los "remedies". En este sentido la parte no incumplidora tiene derecho o bien a daños "no compensatorios" (como son los nominales que conceden indemnizaciones simbólicas o los punitivos que conceden indemnizaciones ejemplificadotas) o a daños "compensatorios". En estos últimos se busca colocar a

25 MEDICUS, Dieter y LORENZ, Stephan. Schuldrecht I. Ed. C. H. Beck. 19 ed. 2010. p. 272.

26 LAMARCA Y MARQUÉS, Albert. “La Modernización del Derecho Alemán de Obligaciones: la Reforma del BGB" en Revista para el Análisis del Derecho, Abril 2001, p. 6, contiene un pormenorizado relato del origen de la solución del BGB original, su interpretación y su reforma. Puede verse en www.indret.com/es/

27 FARNSWORTH, E. Allan. Contracts. 3ra. ed. Aspen Law \& Business. p. 581.

28 CALAMARI, John D. y PERILLO, Joseph M. The Law of Contracts. 4ta. ed. Ed. West Group. 1998. p. 540. 
la parte en la misma posición económica que hubiera alcanzado si el contrato se hubiera cumplido ${ }^{29}$.

Es decir que en este derecho las reglas legales no apuntan al cumplimiento del contrato ("enforcement") sino al establecimiento de reglas ("remedies") para compensar el incumplimiento. Tan es así que el reconocido jurista norteamericano E. Allan Farnsworth sostiene que junto a la libertad contractual existe una "considerable libertad para incumplirlos" ${ }^{\circ}$.

Por su parte el Restatement Second of Contracts, en su numeral 345 al citar los remedios disponibles judicialmente, cita en primer lugar a la indemnización dineraria de los daños. Para este derecho (numeral 344) el interés a reparar puede ser el de expectativa, es decir las ganancias que esperaba obtener del contrato, el de confianza, limitado a los gastos incurridos en atención al contrato celebrado o la restitución de lo dado. Con lo que se ve que la indemnización en el interés de expectativa ("expectation interest") en modo alguno limita la reparación al daño al interés negativo, concepto que sería más afín al "reliance interest".

El Uniform Commercial Code de Estados Unidos de Norteamérica en el numeral 2-703 prevé, entre los remedios a que puede acudir el vendedor frente al incumplimiento del comprador, que éste puede extinguir el contrato ("cancel") y además que puede reclamar indemnización de daños. Similares derechos corresponden al comprador frente al incumplimiento del vendedor, acorde al numeral 2-711 de ese código.

\section{Resolución en las normas del Código Civil}

A esta altura de la argumentación, me parece oportuno recordar algunos textos básicos de nuestro Código Civil. En este sentido, aparece como central lo dispuesto en el art. 519 en el que el concepto de "daños e intereses" se extiende a las pérdidas y a "la utilidad que haya dejado de percibir el acreedor..." (lucro cesante).

Como dijimos en el caso de la extinción del contrato por vía del pacto o la facultad comisoria ex art. 1204 del C. Civil, el deudor ha obrado de manera culposa (en sentido amplio). Por tanto, aparece oportuno recordar lo que establece el art. 511 de ese Código: El deudor de la obligación es también responsable de los daños e intereses, cuando por culpa propia ha 
dejado de cumplirla, el que en gran medida coincide con la solución establecida en el art. 506 para el deudor que actúa dolosamente. La solución es muy distinta, también frente al caso de extinción del contrato, pero sin culpa, como es el caso fortuito o la fuerza mayor. El art. 513 expresamente prevé que en este caso el deudor no será responsable de daños e intereses. Lo mismo sucede frente a los casos de imposibilidad de ejecución de la obligación (arg. arts. 627 y 628) en los que se produce la extinción -sin culpa- y no hay obligación de indemnizar.

Con lo que decimos, reforzado por el propio texto del art. 1204 del C. Civil, lleva a la conclusión indudable de que cuando el deudor incumple y ese incumplimiento puede atribuírsele (aún objetivamente), deberá indemnizar las consecuencias que se encuentren en relación adecuada de causalidad, lo que comprende el daño emergente y el lucro cesante realmente sufrido y probado, con las limitaciones que hemos visto derivadas de los efectos restitutorios.

\section{El nuevo Código Civil y Comercial Unificado, Ley 26.994}

El nuevo Código contiene un Capítulo 13 en la teoría general del contrato, dedicado exclusivamente a la extinción, modificación y adecuación del contrato. Sobre el tema que nos ocupa aparece claro que la nueva normano supera todo prejuicio acerca de la cuestión de la subsistencia de los efectos de un contrato extinguido, incluso retroactivamente. Esto se deja ver claramente en el inc. h del art. 1078 que establece que "la extinción del contrato deja subsistentes las estipulaciones referidas a las restituciones, a la reparación de los daños, a la solución de controversias y a cualquier otra que regule los derechos y obligaciones de las partes tras la extinción".

Por lo demás, el art 1082 del Código se refiere específicamente al tema de la reparación del daño ante la extinción del contrato. Allí realiza una remisión a la regulación unificada que el mismo cuerpo realiza de la responsabilidad civil. Esto nos permite inferir que la ante la extinción del contrato corresponde la reparación integral, siempre que se encuentren reunidos los demás recaudos de la responsabilidad civil. Adicionalmente el Código aclara que la reparación incluye -pero no se limita a ello- el reembolso de gastos $y$, siendo que el Nuevo Código, no recibe expresamente la categoría del "daño al interés negativo" ni siquiera para el ámbito específico de la responsabilidad precontractual (arts. 990 y cc.) no cabe traerla analógicamente a un ámbito como el de la responsabilidad contrac- 
tual que debería ser extraño a él. Los arts. 1740 y 1747 del nuevo cuerpo parecen orientados en el sentido de la no limitación de los daños indemnizables, al consagrar el principio de la reparación plena y de la acumulación del daño moratorio con el compensatorio o el valor de la prestación.

La nueva legislación coloca al tema en lo que entendemos es la senda correcta y no limita la reparación de daños cuanto un contrato se extingue por resolución, como consecuencia del incumplimiento, ya que como dijimos al hacer en el inc. a) del nuevo art. 1082 una remisión a la responsabilidad civil general, nada pareciera indicar en el sentido de la aplicación del concepto restrictivo del daño al interés negativo.

\section{Referencias bibliográficas}

ACUÑA ANZORENA, Arturo. “La Previsibilidad como Límite de la Obligación de Resarcimiento en la Responsabilidad Extracontractual" en Estudios sobre la Responsabilidad Civil. ed. Plantense. 1963.

ALTERINI, Atilio A. Contratos. Abeledo Perrot. BREBBIA, Roberto. Responsabilidad Precontractual. ed. La Rocca, 1987.

CALAMARI, John D. y PERILLO, Joseph M. The Law of Contract. 4ta. ed. Ed. West Group. 1998

CORNET, Manuel. Efectos de la Resolución de los Contratos por Incumplimiento. Ed. Marcos Lerner.

FARNSWORTH, E. Allan. Contracts. 3ra. ed. Aspen Law \& Business. p. 581.

GÓMEZ POMAR, Fernando. “El incumplimiento contractual en Derecho Español" Revista para el Análisis del Derecho. Barcelona. Julio de 2007

LAMARCA Y MARQUÉS, Albert. “Entra en vigor la ley de modernización del derecho alemán de obligaciones" en
Revista para el Análisis del Derecho, 10/1/2002. Puede verse en www. indret.com/es.

LLAMBÍAS, Jorge J. Tratado de Derecho Civil Obligaciones. T I. Ed. Perrot. 5ta. ed.

MACNEIL, Ian. The Relational Theory of Contract. Sweet \& Maxwell. 2001.

MEDICUS, Dieter y LORENZ, Stephan. Schuldrecht I. Ed. C. H. Beck. 19 ed. 2010. p. 272.

MÉNDEZ SIERRA, Eduardo Carlos. “El Daños Contractual Resarcible "Hadley v. Baxendale" y nuestro art. 520 del Cód. Civil” en El Derecho. T. 200. p. 38. MOSSET ITURRASPE, Jorge. “Incumplimiento, resolución y lucro cesante" en La Ley 1990-D, 1064

PANTALEÓN, Fernando. “Resolución por Incumplimiento e Indemnización" en Anuario de Derecho Civil 1989, IV, p. 1150.

POSNER, Richard A. Economic Análisis of Law. Ed. Aspen Law. 5ta. ed. 
SOLER PRESAS, Ana. “La indemnización por resolución del contrato en los PECL/ DCFR" en Revista para el Análisis del Derecho. Barcelona, mayo de 2009.

TRIGO REPRESAS, Félix A. y LÓPEZ MESA, Marcelo J. Tratado de la Responsabilidad Civil. T. II. Ed. La Ley.

VAZQUEZ FERREYRA, Roberto. “Incumplimiento Contractual y Responsabilidad por Daños" en La Ley Litoral, 1997, 185. 


\section{Rodrigo Martín Pellejero}

Abogado recibido en la Facultad de

Derecho de la Universidad Nacional de

Rosario, Magister en Filosofía del Derecho

- UNR, Profesor Adjunto, Derecho Civil III

en la Universidad Nacional de Rosario,

Profesor Titular Asociado de Contratos

Civiles y Comerciales, Universidad Abierta

Interamericana, Profesor Titular Asociado

Derecho del Consumidor, Universidad

Abierta Interamericana.

\section{REGISTRO BIBLIOGRÁFICO}

Rodrigo Martín Pellejero

"DAÑOS Y PERJUICIOS EN LA RESOLUCIÓN CONTRACTUAL POR INCUMPLIMIENTO.

REVISITANDO EL PLENARIO “CIVIT”, MÁS DE VEINTE AÑOS DESPUÉS, A LA LUZ DELNUEVO

CÓDIGO CIVIL Y COMERCIAL", en Papeles del Centro de Investigaciones, Facultad de

Ciencias Jurídicas y Sociales, UNL, publicación semestral, año 6, número 17,

Santa Fe, República Argentina, 2016, pp. 107-125. 